Research Article

\title{
Spectra of bacterial growth in ulcers
}

\author{
Bhagat V. ${ }^{1}$, Brahmachari S. ${ }^{2}$ \\ ${ }^{1}$ Dr. Vaishali Bhagat, Assistant Professor, Department of Surgery SSIMS, Junwani, Bhilai, ${ }^{2}$ Dr. Swagata Brahmachari, \\ Associate Professor, Department of Surgery AIIMS, Bhopal, MP, India
}

Corresponding Author: Dr. Vaishali Bhagat, Assistant Professor, Department of Surgery, SSIMS, Junwani, Bhilai (C.G.) India. E-mail: pappalb@yahoo.co.in

\begin{abstract}
Objectives: To study the spectra of bacterial growth in ulcers in patients and to compare the range and efficacy of Povidoneiodine, Nitrofurazone and silver sulphadiazine with Metronidazole with sucralfate as topical agents. Methods: 100 patients with different types of ulcers with either foul smell or showing response to systemic or local treatment were selected and divided into two groups. Study Group or Group A: 1\% Metronidazole gel with sucralfate. Control group or Group B: for burns and scalds silver sulphadiazine, for trophic ulcers nitofurazone (Furacin ${ }^{\mathrm{R}}$ ) ) in remaining types of ulcer/wounds Povidone iodine (Betadine ${ }^{\mathrm{R}}$ ) ointment was used. Periodic debridement of ulcer/wound was done in both the groups as per requirement. Other general and specific treatment of the patient with regard of his illness was same in both the groups. Systemic antibiotics were given, bacteriological and clinical assessment was daily done. Results: $93 \%$ of cases in Group A and 42\% in Group B showed grade III healing within 35 days. Healing was over all faster in Group $\mathrm{C}$ and 95\% reached grade III within 35 days. One patient in Group B died after 24 days with no signs of healing and remaining 18 patients were converted to Group $\mathrm{C}$ after 45 days of treatment. In Group $\mathrm{C}$ one patient absconded with grade II healing. Conclusion: It was observed that results with topical Metronidazole with sucralfatewere definitely superior as compared to Povidone iodine, Nitrofurazone or Silver sulfadiazine.
\end{abstract}

Keywords: Povidone iodine, Nitrofurazone, Silver sulphadiazine, Metronidazole with sucralfate

\section{Introduction}

The response of living tissues to injury forms the foundation of all the surgical practice. In fact tissue injuries and its sequalae determine the outcome of a majority of clinical problems. Since ages surgery has been progressing like other sciences, on the shoulders of "searchers and researchers" to overcome the problems of infection and to make surgery safe.

Any breach in the continuity of skin or mucous membrane, usually by progressive destruction of surface has always been in central consideration in surgical practice because it exposes the deeper structures to the danger of infection. Simple clean wounds do not pose much problems as open wounds, especially those with tissue loss. These usually heal by secondary intention, contraction and epithelization of the wounds, assuming a more prominent role. If the area is too large to be covered with epithelization and contraction, the wound become a chronic open ulcer.

Manuscript Received: $14^{\text {th }}$ July 2019

Reviewed: $24^{\text {th }}$ July 2019

Author Corrected: $30^{\mathrm{h}}$ July 2019

Accepted for Publication: $6^{\text {th }}$ August 2019
Chronic ulcerremains one of the costliest unsolved problems in the health care, accounting about $15 \%$ of the diabetic patients, who finally results in amputation. In addition, $85 \%$ of paraplegic, chronically ill patients and comatose patients develop pressure sores. Chronic ulcers are painful and usually refractory to treatment. They have some underlying pathologic problem which requires proper clinical diagnosis and management. With proper clinical management most chronic ulcers heal, thereby reducing the morbidity, monetary and manual load on hospitals[1,2].

Management and treatment of ulcers, especially chronic ones, pose a major problem to the treating surgeon. Treatment of the underlying cause is one, and local treatment is another. The main objectives of local treatment are to remove the slough and stimulate the formation of granulation tissue and epithelization and to combat the infection and reduce the growth of bacteria [3]. Most of the surgical wounds and chronic ulcers are contaminated by mixed flora of bacteria. Anaerobes with facultative gram-negative anaerobes have been 


\section{Research Article}

found in venous ulcers, decubitus ulcers, diabetic foot infection and wounds of human and animal bite. Burns are also found to be secondarily infected with anaerobes. Local antibiotics are therefore, used to assist the patient's immune system to prevent or control infection and sepsis especially in large ulcers and burns.

Systemic antibiotics do not penetrate granulation tissue and moreover, in patients with ischaemic ulcers, the systemic antibiotics do not reach the site in adequate concentration because of improper circulation. In such cases role of local antibiotics is emphasized.

These agents can reduce the bacterial count and also provide a moist environment which enhances granulation tissue growth and re-epithelization of partial thickness wounds. Antibiotics gels also accelerate the rate of penetration of antibiotics into granulation tissue. Slow and gentle debridement of the wounds can be accomplished by these gels. They decrease pain and do not adhere to the wound[4].

Metronidazole was introduced first in 1956 and since then it has been widely used in the treatment of facultative and true anaerobes, both gram positive and gram negative. Not only it controls the anaerobic infection, but also breaks the synergism of aerobes and anaerobes in mixed infections. Its notable success in the management of postoperative and other anaerobic sepsis when used systemically, has encouraged to formulate this drug for the topical treatment of chronic ulcers and postoperative wounds, commonly infected with mixed flora of aerobes and anaerobes[5].

After the initial work by P.H. Jones et al with topical Metronidazole, various workers have tried this drug on different types of ulcers topically. Gradually the awareness of usefulness of topical Metronidazole is growing, not only in surgical patients but also in patients with inflammatory lesions of face like acne and rosacea and in dental patients with post extraction sockets.

Also it has been found to be effective in removing the fuel smell in ulcers and fungating tumours [6]. Keeping this in mind present study is undertaken to evaluate the role of topical Metronidazole along with other antimicrobials in chronic non healing ulcers and post operative wounds.

\section{Materials and Methods}

Study design/Type of study - Prospective, randomized, single blinded study.
Sample size \& duration of study- In the present study, total 100 cases with different types of chronic ulcers and wounds and with varying severity of infection, who were admitted in surgical wards in aspan of two years.

Inclusion \& exclusion criteria: 100 patients with different types of ulcers with either foul smell or showing response to systemic or local treatment were selected and divided into two groups.

Study group or group A: This group comprises of patients with chronic infected wounds, pressure ulcers, venous ulcers, diabetic ulcers, trophic ulcers and burns and scalds, each one forming one subgroup, Every wound/ ulcer was washed daily with normal saline, made dry and $1 \%$ Metronidazole sucralfate gel was applied over it in a thin film, twice a day. The second application was made after cleaning the first application. Wound/ulcer was dressed with few gauze pieces and a light bandage after each application.

Control group or group B: This group also comprises of similar type of ulcers as in study group, which were washed with normal saline, allowedto dry and the conventional topical agent, already in use, for the particular ulcer was used. Like for burns and scalds silver sulphadiazine, for trophic ulcers nitofurazone (Furacin $(\mathrm{R})$ ) in remaining types of ulcer/wounds Povidone iodine (Betadine( $\left.{ }^{\mathrm{R}}\right)$ ) ointment was used. Twice application of topical agent was made and wound/ulcer was dressed each time.

\section{Data collection procedure}

1. Each patient, selected for the study had a proforma included in his case records. All data, right from the date of admission to the date of discharge, were recorded, which included name, age, sex, address, registration number and other personal data related to patient's illness.

2. All details regarding ulcer, that is, onset, duration pain, discharge etc were noted in the history of patient's illness.

3. Pretreatment culture was taken and then wound or ulcer was examined closely after cleaning it with normal saline, to record all findings in order to see the changes in healings following investigations.

Data analysis: The various statistical techniques i.e. the mean, standard deviation and test of significance (t-test and chi-square-test) were used for drawing valid conclusions.Statistical analysis done using student ttest. SPSS 13.0 software was used to calculate $\mathrm{p}$ value. 


\section{Research Article}

Surgical proceduresdone- Periodic debridement of ulcer/ wound was done in both the groups as per requirement. Other general and specific treatment of the patient with regard of his illness was same in both the groups like:

For pressure ulcer - back care, cushions and high protein diet.

For venous ulcer - complete bed rest, foot elevation, crepe bandage etc.

For trophic ulcer - all the patient were on antileprosy treatment and were allowed to walk.

For diabetic ulcer - diabetic diet, oral hypoglycaemic or insulin to keep blood sugar within normal limits.

Burns - High proteins diet, multivitamins, analgesics.

Systemic antibiotics: To start with, all patients were given a combination of ampicillin and gentamicin. Cultures were taken from the ulcer/wound every 7-10 days interval till it became sterile or clinically no discharge was present. Sensitivity of the organism grown was seen and that antibiotic was given to the patient.

Bacteriological assessment- In every 7 to 10 days, culture was taken from the ulcer/wound. Since facilities for anaerobe culture are not available, bacteriological culture for aerobes was only done. The characteristic putrid odour, when present, and failure of ulcer/wound to heal inspite of adequate treatment, was taken as sufficient indication of the presence of anaerobic organisms.

Clinical assessment: Daily observation of wound/ulcer was made. The recording were made of the changes occurring every week as well as the first day of the following events were noted.

\section{Disappearance of smell}

\section{Disappearance of pus}

3. Appearance of pink and then red granulation tissue.

4. Starting of epithelization

Smell was assessed also by the patient, patient's attendant and the house surgeon in-charge of the patient and was graded as follows: a) No odour even at a close range - 0

b) Faint odour detected only at close range with dressing removed $\geq(+)$.

c) Moderate odour detected at about 6 feet with dressing removed $\geq(++)$.

d) Strong odour noted in room even when dressing in situ $\geq(+++)$

Appearance of ulcer was assessed and graded as follows.

1. Ulcer healed -(IV)

2. Marked evidence of healing - ulcer healing with marked red granulation tissue. No slog H - (III)

3. Beginning to heal - minor degree of pink granulation tissue, floor of ulcer sloughing -- -(II)

4. No signs of healing - edema and cellulitis of surrounding tissue, base of ulcer shows well marked slough - - (I).

In both groups, patients were treated with the respective agents for a period of 3 weeks to 6 weeks and if no satisfactory improvement was seen in the wound of ulcer, the topical agent was changed. All these cases were considered in group $\mathrm{C}$ or conversion group. All these patients were treated on similar lines as in group $\mathrm{A}$ and $\mathrm{B}$ and observations of the ulcer/wound was also made on similar points as cited above.Each case was followed up for clinical \&bacteriological outcome till it was discharged or some surgery was done to cover the ulcer/wound.

Statistical analysis- After getting the required information, the collected data were coded, tabulated and analysed. The various statistical techniques i.e. the mean, standard deviation and test of significance ( $\mathrm{t}$-test and chi-square-test) were used for drawing valid conclusions.Statistical analysis done using student ttest. SPSS 13.0 software was used to calculate $p$ value. $\mathrm{P}<0.05$ was taken as statistically A descriptive analysis was done on all variables to obtain a frequency distribution.

The mean + SD and ranges were calculated for quantitative variables. Continuous variables were compared by the Student $t$ test. Proportions were analyzed with the chi-square test

\section{Results}

The present clinicomicrobiological study of 100 cases was done to compare the effects of various conventional topical agents Povidone iodine $\left(\right.$ Betadine $\left.^{\mathrm{R}}\right)$, Nitrofurazone $\left(\right.$ Furacin $\left.^{\mathrm{R}}\right)$, and silver sulphadiazine and Metronidazole sucralfate on healing of burns and chronic wounds \& ulcers of diverse etiologies. 
Table-1: Distribution of cases.

\begin{tabular}{|c|c|c|c|c|c|c|}
\hline \multirow{2}{*}{ Total } & \multicolumn{2}{|c|}{ Group A } & \multicolumn{2}{c|}{ Group B } & \multicolumn{2}{c|}{ Group C } \\
\cline { 2 - 7 } & No. & $\%$ & No. & $\%$ & No. & \% \\
\hline 100 & 53 & 53 & 47 & 47 & 18 & 37.8 \\
\hline
\end{tabular}

Table-2: Distribution of cases in various subgroups

\begin{tabular}{|c|c|c|c|}
\hline $\begin{array}{c}\text { Type of ulcer } \\
\text { (Sub groups) }\end{array}$ & Group A & Group B & Total A+B \\
\hline Pressure ulcer (1) & 10 & 04 & 20 \\
\hline Diabetic ulcer (2) & 08 & 08 & 20 \\
\hline Trophic ulcer (3) & 12 & 17 & 32 \\
\hline $\begin{array}{c}\text { Non healing (4) } \\
\text { Traumatic/Postp. }\end{array}$ & 15 & 04 & 08 \\
\hline Venous ulcer (5) & 04 & 04 & 08 \\
\hline Burns \& Scalds (6) & 04 & & 12 \\
\hline
\end{tabular}

The table below shows that maximum patients were of non healing, chronically infected wounds, either postoperative or traumatic

Table-3: Chronicity of ulcer/wound

\begin{tabular}{|c|c|c|c|c|c|c|c|}
\hline \multirow{2}{*}{ Group } & \multicolumn{7}{|c|}{ Duration of ulcer } \\
\cline { 2 - 9 } & $\mathbf{0 - 1 5}$ days & $\mathbf{1 6 - 2 9}$ days & $\mathbf{1 M - 3 M}$ & $\mathbf{4 M - 6 M}$ & $\mathbf{7 M - 1 1 M}$ & $\mathbf{1 Y R - 2 Y R}$ & > 2YR \\
\hline A & 20 & 19 & 09 & 02 & 01 & 01 & 01 \\
\hline B & 18 & 15 & 10 & 02 & 01 & 01 & 01 \\
\hline Total & 38 & 34 & 19 & 04 & 02 & 02 & 02 \\
\hline
\end{tabular}

This table is showing that $72 \%$ of cases were of duration of less than a month.

Bacteriological assessment- Bacteriology of wounds was assessed by culturing the swabs from wounds, findings, the organism and assessing their sensitivity to various antibiotics.

Table-4: Frequency of organism in various groups.

\begin{tabular}{|c|c|c|c|c|c|}
\hline \multirow{2}{*}{$\begin{array}{c}\text { Type of } \\
\text { organism }\end{array}$} & \multicolumn{2}{|c|}{ Total } & Group A & Group B & Group C \\
\cline { 2 - 6 } & No. & \% & & & 06 \\
\hline E.Coli & 35 & 35.00 & 22 & 13 & 01 \\
\hline Pseudomonas & 09 & 09.00 & 04 & 05 & 01 \\
\hline Proteus & 09 & 09.00 & 08 & 09 & 05 \\
\hline Staphylococcus & 16 & 16.00 & 07 & 07 & 01 \\
\hline Streptococci & 14 & 14.00 & 07 & 12 & 04 \\
\hline Klebsiella & 17 & 17.00 & 05 & 09 & \\
\hline
\end{tabular}


Table-5: Distribution of cases with resistant organism

\begin{tabular}{|c|c|c|}
\hline Group & No. of Cases & Percentage \\
\hline Group A (53) & 39 & $74.10 \%$ \\
\hline Group B (47) & 22 & $46.20 \%$ \\
\hline Total (100) & $\mathbf{6 1}$ & $\mathbf{6 1 . 0 0 \%}$ \\
\hline
\end{tabular}

\section{Clinical Assessment}

The ulcers and wounds were assessed clinically on following parameters.

1. Disappearance of smell.

2. Disappearance of pus.

3. Starting of epithelization.

4. Appearance of pink and red granulation tissue.

Table-6: Average period (in days) for disappearance of pus

\begin{tabular}{|c|c|c|c|c|c|c|}
\hline Groups & \multicolumn{7}{|c|}{ Sub Groups } \\
\hline & I & II & III & IV & V & VI \\
\hline Group A & 22.50 & 14.50 & 14.67 & 13.27 & 12.00 & 18.50 \\
\hline Group B & 27.86 & 25.50 & 12.75 & 23.57 & 23.00 & 25.25 \\
\hline Group C & 11.00 & 10.00 & 16.00 & 11.80 & 100.00 & 00.00 \\
\hline
\end{tabular}

Table-7: Average period (in days) for appearance of red granulation

\begin{tabular}{|c|c|c|c|c|c|c|}
\hline Groups & \multicolumn{7}{|c|}{ Sub Groups } \\
\hline & I & II & III & IV & V & VI \\
\hline Group A & 19.00 & 15.12 & 15.42 & 12.00 & 109.50 & 17.00 \\
\hline Group B & 25.30 & 25.00 & 13.00 & 21.70 & 18.50 & 21.50 \\
\hline Group C & 11.70 & 10.00 & 16.00 & 09.50 & 00.00 & 00.00 \\
\hline
\end{tabular}

Table-8: Average period (in days) for appearance of epithelization.

\begin{tabular}{|c|c|c|c|c|c|c|}
\hline Groups & \multicolumn{9}{|c|}{ Sub Groups } \\
\hline & I & II & III & IV & V & VI \\
\hline Group A & 13.60 & 12.30 & 13.40 & 11.20 & 109.25 & 14.00 \\
\hline Group B & 21.40 & 19.00 & 19.80 & 23.70 & 15.25 & 16.00 \\
\hline
\end{tabular}

Table -9: Results at 21 And 45 days.

\begin{tabular}{|c|c|c|c|c|c|c|}
\hline Groups & $\begin{array}{c}\text { Partially 21 } \\
\text { days }\end{array}$ & $\begin{array}{c}\text { Healed 45 } \\
\text { days }\end{array}$ & $\begin{array}{c}\text { Completely } \\
\text { 21 days }\end{array}$ & $\begin{array}{c}\text { Healed 45 } \\
\text { days }\end{array}$ & \multicolumn{2}{|c|}{$\begin{array}{c}\text { Not healed } \\
\text { 21 days45 days }\end{array}$} \\
\hline Group A (53) & 21 & 18 & 17 & 34 & 15 & 01 \\
& $39.50 \%$ & $33.50 \%$ & $32.30 \%$ & $64.60 \%$ & $28.20 \%$ & $01.90 \%$ \\
\hline Group B(47) & 16 & 16 & 02 & 12 & 29 & 19 \\
& $33.80 \%$ & $33.80 \%$ & $04.30 \%$ & $25.20 \%$ & $61.90 \%$ & $41.00 \%$ \\
\hline Group C(18) & 10 & 08 & 06 & 09 & 02 & 01 \\
& $55.50 \%$ & $44.50 \%$ & $33.20 \%$ & $50.00 \%$ & $11.30 \%$ & $05.50 \%$ \\
\hline
\end{tabular}




\section{Research Article}

Bacteriological results- This was assessed by noting the average time taken by an ulcer/wound, infected by a particular organism to reach grade III healing and by calculating the number of cases with persistent infection after fourth culture.

- Smell persistence rate was 33.3\% in Group B whereas 0\% in Group A. All 33.3\% cases of group B when converted to Metronidazole responded with disappearance of smell in an average period of 4.59 days.

- It was observed that Metronidazole alone was better than Povidone iodine in infection with E. Coli, Proteus, Klebsiella and Streptococci and similar to Povidone iodine in case of Staphylococcal and Pseudomonas infection. It was interesting to note that use of two drugs alternatively was more effective in treatment of Staphylococcus aureus, Pseudomonas, Streptococci and Proteus than any of the drug when used alone.

- Persistent infection rate after one month of treatment was very less with Metronidazole alone (9.5\%) or in combination (5.5\%) than conventional topical agent alone $(27.3 \%)$.

- After 45 days of treatment with particular agent, it was seen that $98 \%$ of cases were either completely or partially healed with Metronidazole alone where as it was $60 \%$ with conventional topical agent. All the cases in which treatment was changed, showed $95 \%$ results.

\section{Discussion}

The present study was carried out to evaluate the efficacy of topical Metronidazole 1\% in gel form in infected chronic ulcers and wounds of various etiologies. Healing cannot take place until all bacteria have been eliminated by the humoral and cellular host defenses. These ulcers are resistant to treatment with routine antibiotics drug is of immense value in these patients. Metronidazole is the drug of choice in the management of patients with anaerobic infections since it has the widest anaerobic spectrum [6].

Edwards $\mathrm{R}$ et al did areview on bacteria and wound healing. Wound healing is a complex process with many potential factors that can delay healing. To summarize, an appreciation of the factors affecting the progression from colonization to infection can help clinicians with the interpretation of clinical findings and micro-biological investigations in patients with chronic wounds. An understanding of the physiology and interactions within multi-species biofilms may aid the development of more effective methods of treating infected and poorly healing wounds. The emergence of consensus guidelines has helped to optimize clinical management [7].

Topical antimicrobial therapy for treating chronic wounds was studied by Lipsky BA, Hoey C. Topical therapy affords many potential advantages but also has disadvantages. Opinions differ on which clinical signs define wound infection and on whether quantitative microbiological studies are useful. Clinically infected wounds usually require systemic antibiotic therapy, whereas clinically uninfected wounds that are healing as expected do not require antimicrobials. This study provided clinically relevant information on currently available topical antimicrobial agents[8].
Siddiqui AR et al studied the facts and controversies associated with Chronic wound infection. Chronic wound infections are responsible for considerable morbidity and significantly contribute to the escalation in the cost of health care. Wound infection may initially be manifest as bacterial colonization, and it is only when colonization is combined with other factors, such as decreased vascular supply, intrinsic virulence of specific bacteria (eg, Staphylococcus aureus), and host immune factors, that true infection occurs. In many instances, it is appropriate to treat these wounds empirically with a combination of topical antiseptics and systemic antibiotics, especially in the presence of invasive infections[9].

Watcher MA et al studied the role of topical agents in the healing of full-thickness wounds. Eight topical agents in current use were studied for their effects on wound contraction and rate of re-epithelialization of full-thickness excisions using a porcine animal model. The rate of reepithelialization was significantly enhanced by treatment with capsaicin, bacitracin, silver sulfadiazine, and scarlet red, and was markedly retarded by treatment with tretinoin. Wound contraction was significantly retarded by mupirocin, bacitracin, and silver sulfadizine. Knowledge of the effects of topical agents on various aspects of healing allows the clinician to choose the most appropriate material to use in a given clinical situation to optimize the healing process and produce the best final result. [10]

Nygaard $\mathrm{K}$ et al in their study published inscandinavian journal of gastroenterology used topical metronidazole in treatment of pouchitis. Patients with pouchitis usually respond to oral metronidazole treatment, but side effects of the treatment are common. Eleven patients with 


\section{Research Article}

pouchitis were given local treatment by instillation of metronidazole in doses of $40-160 \mathrm{mg}$ daily into the reservoir. In conclusion, topical application of small doses of metronidazole relieved symptoms in most cases of pouchitis and was well tolerated, even as longterm treatment [11].

Fonder MA, Lazarus GS et al gave apractical approach to the care of nonhealing wounds and wound care dressings. The American Academy of Dermatology has underscored the significance of wound care in dermatological practice. They concluded that it was critical for all dermatologists to understand the elements of diagnosis and therapy. They emphasized themajor aspects of diagnosis and presenteda simple classification of wound dressings with guidelines for usage and relative cost data. After completing this learning activity, participants wouldbe able to diagnose common types of chronic wounds, formulate a therapeutic plan, and describe the major classes of topical therapies and dressings for the chronic wound [12].

A review of the microbiology, antibiotic usage and resistance in chronic skin wounds was done by HowellJones et al. Chronic leg and foot wounds represent an increasing burden to healthcare systems as the age of the population increases. The deep dermal tissues of all chronic wounds harbour microorganisms, however, the precise interaction between microbes in the wounds and impaired healing is unknown. With regard to antibiotic therapy, there is a lack of evidence concerning its effectiveness, optimal regimens or clinical indications for treatment. Despite this lack of evidence, antibiotics are frequently a feature of the management of chronic wounds and these patients receive significantly more antibiotic prescriptions (both systemic and topical) than age and sex-matched patients[13].

Current guidelines for antibiotic prescribing for such wounds are often based on expert opinion rather than scientific fact and may present difficulties in interpretation and implementation to the clinician. Although the increasing prevalence of antibiotic resistance is widely recognized, the relationships between antibiotic resistance, chronic wound microbiology and rationales for antibiotic therapy have yet to be determined. This review discusses the role of microbes in chronic wounds from a clinical perspective with particular focus on the occurrence of bacteria and their impact on such wounds. The evidence and role of antibiotics in the treatment of such wounds are outlined and current practice of antibiotic usage for chronic wounds in the primary care setting described. The implications of antibiotic usage with regard to antibiotic resistance are also considered[14].

Kucan JO did comparison of silver sulfadiazine, povidone-iodine and physiologic saline in the treatment of chronic pressure ulcers. The presence of bacteria and local infection is an important factor in the local management of chronic pressure ulcers. For successful closure of the ulcer, the bacterial count should be $10^{5}$ or less per gram of tissue in the granulating wound. The ulcers treated with silver sulfadiazine cream responded more rapidly, with one-third showing bacterial levels of $<10^{5}$ within three days, and half within a week[15].

O' Meara S et al did asystematic reviews of wound care management. Similar study was also done by Ousey K et al in which they studied topical antimicrobial agents for the treatment of chronic wounds.Chronic wounds, including pressure sores, leg ulcers, diabetic foot ulcers and other kinds of wounds, healing by secondary intention are common in both acute and community settings. Antibiotic resistance has become a major medical and public health problem, and interest has been generated in the use of topical therapies to manage wound infection. This article presents an overview of the historical use of honey, silver and iodine for the treatment of infected wounds progressing through to modern day use and the current evidence base for the use of these antimicrobial agents in the management of infected wounds[16,17].

McDonald A et al in their study onpalliative management of pressure ulcers and malignant wounds in patients with advanced illness inferred that the goals of care may shift from a primary focus on healing to a focus on wound management, palliation and comfort. The ultimate goals of palliative wound care are to control pain, to manage infection, odor, bleeding, and exudate, and to maintain a good quality of life for the patient and caregiver[18].

Powers JG et al in their work onwound healing and chronic wound care and management. They concluded that chronic ulcers-including decubitus, vascular, inflammatory, and rheumatologic subtypes - affect $>6$ million people, with increasing numbers anticipated in our growing elderly and diabetic populations. These wounds cause significant morbidity and mortality and lead to significant medical costs. Preventative and treatment measures include disease-specific approaches and the use of moisture retentive dressings and adjunctive topical therapies to promote healing. In this 


\section{Research Article}

article, we discuss recent advances in wound care technology and current management guidelines for the treatment of wounds and ulcer [19].

Alvarez OM, Kalinski C et al emphasized incorporating wound healing strategies to improve palliation (symptom management) in patients with chronic wounds. Palliative wound care should be centered on symptom management and is a viable option for patients whose chronic wounds do not respond to standard interventions, or when the demands of treatment are beyond the patient's tolerance or stamina.

A practical marriage of wound palliation (symptom management) with current wound healing concepts to provide options for the palliative care provider and improve the practice of palliative medicine [20].

\section{Limitation of the present study}

1. Small sample size

2. Chances of bias

3. Single center trial

\section{Conclusion}

1. Metronidazole is a powerful and equally effective anaerobicidal drug when used topically, as it is in systemic use as smell disappeared faster than that with other agents.

2. Topical Metronidazole was found to be definitely efficacious in treating chronic ulcers as pus and slough cleared faster with earlier appearance of healthy granulation tissue as compared to wound/ ulcers treated with different ointments topically, and no conversion was needed. Also the failures of other topical agents showed healing with Metronidazole.

3. Persistent infection rate was very much less with Metronidazole as compared to conventional topical agent.

4. Topical Metronidazole done not have the systemic side effects as are present with its oral or intravenous administration. So it is comparatively safe.

\section{What thestudy adds to the existing knowledge?}

Thus Metronidazole with sucralfate is highly effective with broad spectrum antimicrobial activity, easily available and safe antimicrobial agent. But since it is used systemically also, its regular topical use might develop resistant strains. So the present study suggests. Metronidazole gel $1 \%$, as the topical antimicrobial of choice in cases of chronic ulcers and wounds with established mixed infection, only when they are not responding satisfactorily to the usual systemic and local treatment.

\section{Author's contribution}

Dr. Vaishali Bhagat: Study design, data analysis and manuscript preparation.

Dr. Swagata Brahmachari: Study design, data analysis and manuscript preparation.

Conflict of interest: None declared.

Funding: Nil, Permission from IRB: Yes

Ethical approval: Taken

\section{References}

1. Baker SR, Stacey MC, Singh G, Hoskin SE, Thompson PJ. Aetiology of chronic leg ulcers. Eur J Vasc Surg. 1992;6(3):245-51.

2. Leigh IM, Purkis PE, Navsaria HA, Phillips TJ. Treatment of chronic venous ulcers with sheets of cultured allogenic keratinocytes. Br J Dermatol. 1987; 117 (5): 591-7. doi: 10.1111/j.1365-2133.1987. tb 07491.x

3. Rahman GA, Adigun IA, Fadeyi A. Epidemiology, etiology, and treatment of chronic leg ulcer: experience with sixty patients. Ann Afr Med. 2010;9(1):1-4. doi: 10.4103/1596-3519.62615.

4. Phillips TJ. Chronic cutaneous ulcers: etiology and epidemiology. J Invest Dermatol. 1994;102(6):38S-41S. doi:10.1111/1523-1747.ep12388556

5. Fu X, Sheng Z, Cherry GW, Li Q. Epidemiological study of chronic dermal ulcers in China. Wound Repair Regen. 1998 ;6(1):21-7.

6. Jones PH, Willis AT, Ferguson IR. Treatment of anaerobically infected pressure sores with topical metronidazole. The Lancet. 1978; 311(8057):214.doi: https://doi.org/10.1016/S0140-6736(78)90654-2

7. Edwards R, Harding KG. Bacteria and wound healing. CurrOpin Infect Dis. 2004;17(2):91-6.

8. Lipsky BA, Hoey C. Topical antimicrobial therapy for treating chronic wounds. Clin Infect Dis. 2009; 49 (10):1541-9. doi: 10.1086/644732. 


\section{Research Article}

9. Siddiqui AR, Bernstein JM. Chronic wound infection: facts and controversies. Clin Dermatol. 2010; 28(5):519-26. doi:10.1016/j.clindermatol. 2010.03. 009

10. Watcher MA, Wheeland RG. The role of topical agents in the healing of full-thickness wounds. J Dermatol Surg Oncol. 1989 ;15(11):1188-95.

11. Eaglstein WH, Falanga V. Chronic wounds. Surg Clin North Am. 1997;77(3): 689-700. doi:10.1016/ s0039-6109 (05)70575-2

12. Nygaard K, Bergan T, Bjørneklett A, Høverstad T, Lassen J, Aase S. Topical metronidazole treatment inpouchitis. Scand J Gastroenterol. 1994;29(5):462-7.

13. Fonder MA, Lazarus GS, Cowan DA, AronsonCook B, Kohli AR, Mamelak AJ. Treating the chronic wound: A practical approach to the care of nonhealing wounds and wound care dressings. J Am Acad Dermatol. 2008;58(2):185-206.doi:10.1016/j.jaad. 2007. 08.048.

14. Howell-Jones RS, Wilson MJ, Hill KE, Howard AJ, Price PE, Thomas DW. A review of the microbiology, antibiotic usage and resistance in chronic skin wounds. J Antimicrob Chemother. 2005;55(2):143-9. Epub 2005 Jan 13. doi:10.1093/jac/dkh513

15. Kucan JO, Robson MC, Heggers JP, Ko F. Comparison of silver sulfadiazine, povidone-iodine and physiologic saline in the treatment of chronic pressure ulcers. J Am Geriatr Soc. 1981; 29(5):232-5. doi:10. 1111/j. 1532-5415.1981.tb01773.x

16. O'Meara S, Cullum N, Majid M, Sheldon T. Systematic reviews of wound care management: (3) antimicrobial agents for chronic wounds; (4) diabetic foot ulceration. Health Technol Assess. 2000;4(21):1237. doi: https://doi.org/10.3310/hta4210

17. Ousey K, McIntosh C. Topical antimicrobial agents for the treatment of chronic wounds. Br J Community Nurs. 2009;14(9): S6, S8, S10 passim. doi:10.12968/ bjcn. 2009.14.Sup4.43909

18. McDonald A, Lesage P. Palliative management of pressure ulcers and malignant wounds in patients with advanced illness. J Palliat Med. 2006;9(2):285-95. doi: 10.1089/jpm.2006.9.285

19. Powers JG, Higham C, Broussard K, Phillips TJ. Wound healing and treating wounds: Chronic wound care and management. J Am Acad Dermatol. 2016; 74 (4): 607-25; quiz 625-6. doi: 10.1016/j.jaad. 2015. 08.070 .

20. Alvarez OM, Kalinski C, Nusbaum J, Hernandez L, Pappous E, Kyriannis C, et al. Incorporating wound healing strategies to improve palliation (symptom management) in patients with chronic wounds. J Palliat Med. 2007;10(5):1161-89. doi:10.1089/jpm.2007.9909

\section{How to cite this article?}

Bhagat V, Brahmachari S. Spectra of bacterial growth in ulcers. Surgical Update: Int J surg Orthopedics. 2019;5(3): 158-166. doi:10.17511/ijoso.2019.i03.06. 